Document downloaded from:

http://hdl.handle.net/10251/99455

This paper must be cited as:

Giner-Sanz, JJ.; Ortega Navarro, EM.; Pérez-Herranz, V. (2014). Hydrogen crossover and internal short-circuit currents experimental characterization and modelling in a proton exchange membrane fuel cell. International Journal of Hydrogen Energy. 39(25):1320613216. doi:10.1016/j.ijhydene.2014.06.157

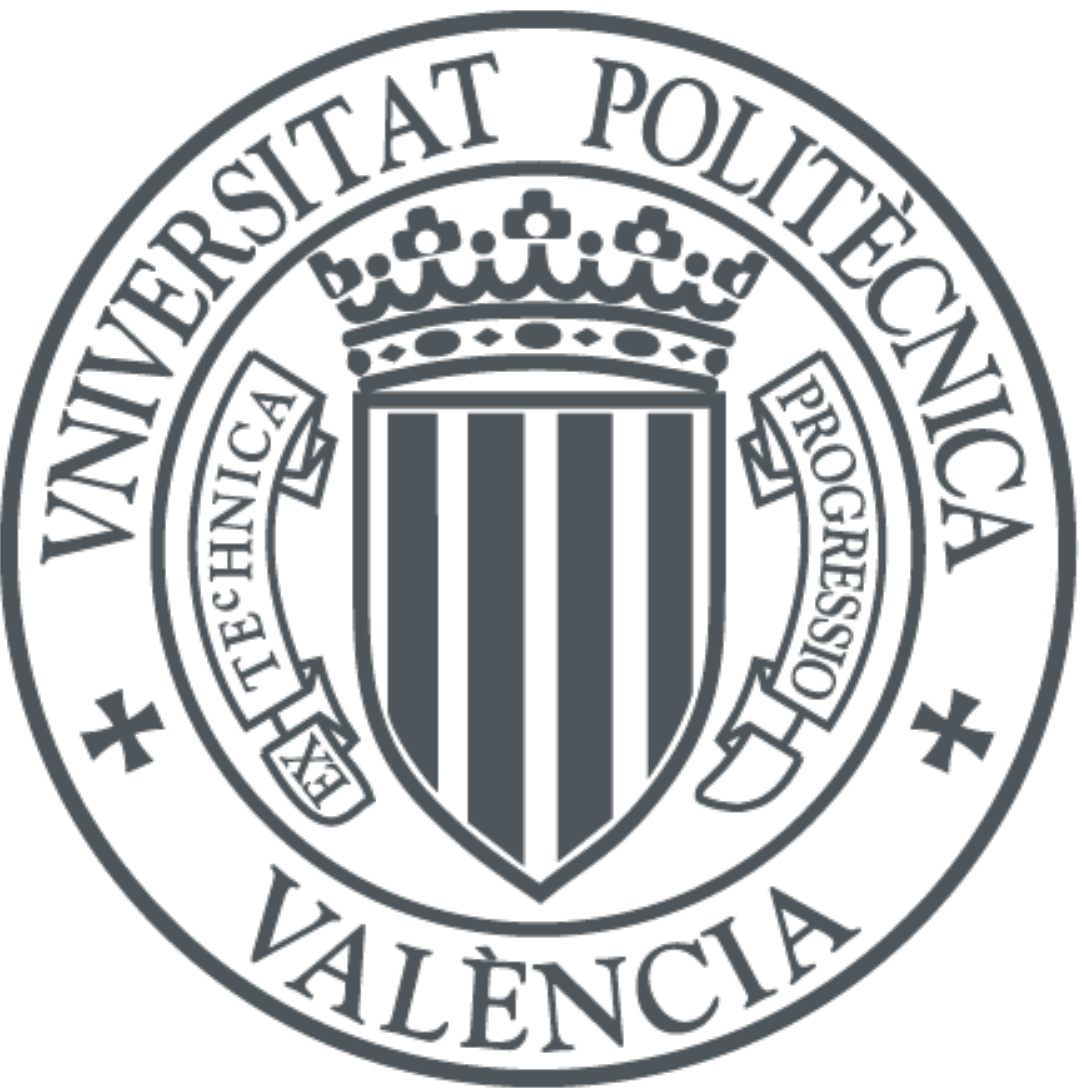

The final publication is available at

http://dx.doi.org/10.1016/j.ijhydene.2014.06.157

Copyright Elsevier

Additional Information 


\title{
Hydrogen crossover and internal short-circuit currents experimental characterization and modelling in a proton exchange membrane fuel cell
}

\author{
J. J. Giner-Sanz, E. M. Ortega, V. Pérez-Herranz \\ IEC group, Depto. Ingeniería Química y Nuclear, Universitat Politècnica de València \\ Camino de Vera S/N, 46022 Valencia, Spain \\ *Corresponding author. Tel.: +34-96-3877632; fax: +34-96-3877639; \\ E-mail address: vperez@iqn.upv.es (V.Pérez-Herranz)
}

Keywords: PEM fuel cells; open circuit losses; hydrogen crossovers; internal shortcircuits; modelling; linear sweep voltammetry.

\section{Abstract:}

Open circuit losses encompass a set of phenomena that reduce PEM fuel cell (PEMFC) efficiency, especially at low current densities. Properly modelling these losses is crucial for obtaining PEMFC models that reproduce accurately the experimental behaviour of PEMFCs operating at low current densities. The open circuit losses can be disaggregated into three distinct contributions: mixed potential, hydrogen crossovers and internal short-circuits. The aim of this work is to obtain a model for the anodic and the cathodic pressure effects on the hydrogen crossovers and the internal shortcircuits in a commercial PEMFC. In order to achieve this goal, the hydrogen crossovers and the internal short-circuit were measured experimentally on a commercial PEMFC by linear voltammetry. The measurements were performed at a given temperature and gas inlet humidification level, for different anodic and cathodic pressures. 


\section{Introduction}

Fuel cells (FCs) are electrochemical devices that are able to transform the energy of a chemical reaction directly into electrical energy [1]. PEM fuel cells (PEMFCs) have attracted a great attention in the last decades as very promising alternatives for power generation devices for automotive, portable and distributed applications; due to their high power density, compactness, light weight and low cost [1]. Great research efforts have been made in recent years in order to increase the power density and the reliability of such fuel cells, and to decrease their cost [2].

One approach to increase the power density is to increase the performance of a single cell, by tackling the different irreversibilities that reduce its power density performance [3]. These irreversibilities are commonly known as voltage drops or overpotentials. The Nernst potential of an individual PEMFC is the theoretical thermodynamic open circuit cell potential that would appear between the terminals of a PEMFC working under certain conditions, and supplying no current (in thermodynamic equilibrium). However, the experimental open circuit cell voltage is lower than the Nernst theoretical potential. This voltage difference is known as open circuit voltage loss. These open circuit losses significantly affect the efficiency of the cell, particularly for cells working at low current densities, where these losses have a more significant effect [4].

The open circuit losses involve three different phenomena: the mixed potential; the gas crossover from the anodic to the cathodic compartment; and the internal shortcircuit currents [5].

On the one hand, for potentials above $0.8 \mathrm{~V}$ (which occur in cells working at low current densities) the platinum of the catalyst layer is not stable and is oxidised, creating a PtO layer that partially covers the catalyst surface. This leads to the appearance of a mixed potential, composed by the potential of the cathodic half reaction $\mathrm{O}_{2} / \mathrm{H}_{2} \mathrm{O}$ and the potential of the anodic half reaction Pt/PtO. This causes a potential drop compared to the pure platinum catalyst layer situation. This phenomenon is known as mixed potential [4].

On the other hand, the polymer membrane is substantially impermeable to the reactant gases. However, small amounts of gases diffuse from one compartment to the other. These diffusive fluxes of gases are called gas crossovers [6]. In principle, all gases in a PEMFC system crossover: hydrogen from the anodic compartment to the cathodic one; and oxygen and nitrogen from the cathodic compartment to the anodic one. However, in practice, the only relevant gas crossover is the hydrogen crossover, since due to its small molecular size the hydrogen crossover flux is several orders of 
magnitude higher than the other gases crossovers [1]. Therefore it is usually assumed that the only gas crossover that exists in a PEMFC is the hydrogen crossover from the anodic compartment to the cathodic one.

Finally, even though the PEM membrane is an electron nonconductive membrane, some electrons can pass through the membrane, creating internal short-circuit currents [5].

Both, the hydrogen crossover and the internal short-circuit currents have equivalent effects on the PEMFC performance: a smaller number of electrons flow through the external circuit. In the internal short-circuit currents case, the electrons that cross directly through the membrane do not flow through the external circuit; whereas in the hydrogen crossover case, the hydrogen diffuses to the cathodic compartment, where it reacts directly, and therefore two electrons that would have flowed through the external circuit if the hydrogen had been oxidised in the anodic compartment, do not circulate through the external electrical circuit [1]. These losses are negligible at high current densities, since the hydrogen permeation rate and the electrical internal short-circuit currents are several orders of magnitude lower than the hydrogen consumption rate and the electric current respectively [2]. Furthermore, an increase in the current leads to a decrease of the hydrogen concentration on the electrode. Therefore the diffusion driving force decreases, and makes even smaller the hydrogen crossover [7].

In brief, these open circuit losses are not significant at high current densities; but they have a substantial effect on the performance at low current densities. The proper modelling of these open circuit losses is critical in order to achieve a model that fits suitably the experimental behaviour of the PEMFC at low current densities.

The general approach used in literature to model the open circuit losses consists in using a black-box model that encompasses all three open circuit losses phenomenons [8]. This kind of model does not allow the discrimination of the individual contributions of each one of the open circuit losses phenomenons; and just quantifies the open circuit losses as a whole. However, the split of the open circuit losses in the different individual contributions can allow a better understanding of the processes involved, which can be used to minimize these open circuit losses thereby increasing the performance of PEMFC at low current densities.

No such open circuit losses splitted models have been found in literature. Zhang measured the different contributions to the open circuit losses [4], but did not establish a model for them. Other works characterised the hydrogen crossovers independently [5-6], but did not deal with the other two phenomenons. 
The present work intends to partially fill this gap in literature, by obtaining a model that discriminates between the different contributions to the open circuit losses. Therefore, the aim of this work is to experimentally characterize and model the effect of the compartment internal pressures on the hydrogen crossovers and the internal short-circuit currents of an individual cell of a commercial PEMFC stack. 


\section{Crossover and short-circuit model}

The hydrogen crossover rate strongly depends on the operating conditions of the PEMFC membrane [9]. Therefore, in order to get more realistic results, it is important to perform the measurements in conditions as similar as possible to the real operation conditions during normal operation of the PEMFC system. This can only be achieved by in-situ measurement methods [5].

The crossover phenomenon is simply a gas permeation phenomenon through a membrane. Numerous techniques have been developed for in situ measurement of gas permeation rates through polymeric membranes, in various fields of application [5]. The most relevant in-situ gas permeation rate measurement techniques, mentioned in literature, are the volumetric method [10-11]; the lag time method [12$13]$; the gas chromatography method [14]; and the electrochemical methods [6, 15].

The only in-situ gas permeation rate measurement methods that can measure in parallel the PEMFC internal short-circuit currents are the electrochemical methods [5]. Since the goal of this work is to characterize both, the hydrogen crossovers and the internal short-circuit currents, this type of methods was selected to perform the measurements of this study.

From all the available electrochemical methods for gas permeation rate measurement, the linear sweep voltammetry is the most simple and straight-forward one [15]. Because of this, it was the selected method for the present study. Figure 1 shows the setup of the in-situ linear sweep voltammetry method. The PEMFC is fed with humidified hydrogen to the anodic compartment; and with humidified nitrogen to the cathodic compartment. A known potential difference is applied to the terminals of the PEMFC using a potentiostat. The polarity of the connection is selected properly in order to oxidize the hydrogen crossovers, when they arrive to the PEMFC cathodic compartment. Therefore during the in-situ measurement the PEMFC cathodic compartment acts as anode; whereas the PEMFC anodic compartment acts as cathode. In this work, the normal operation compartment nomenclature will be used. An increasing linear applied potential sweep is performed, measuring the current intensity for each applied potential.

\subsection{Equivalent electrical circuit}

As described previously, two phenomena occur simultaneously, in parallel: the hydrogen crossovers and the electrical internal short-circuits. Electrically, the internal short-circuits behave as a short-circuit resistance between the electrodes of the PEMFC. So the two phenomenons can be modelled by an equivalent electrical circuit 
consisting in a short-circuit resistance in parallel with a crossover element, as shown in figure 2. This equivalent electric circuit was introduced by Kocha [5].

According to Kirchoff's current law:

$$
I=I_{S C}+I_{\text {Cross }}
$$

Where I denotes the total electrical current associated with the hydrogen crossover oxidation and the internal short-circuit; $I_{S C}$ represents the internal short-circuit current; and $I_{\text {Cross }}$ is the electric current due to the oxidation of the hydrogen crossovers.

On the one hand, the internal short-circuit current can be expressed using Ohm's law:

$$
I_{S C}=\frac{U_{S C}}{R_{S C}}
$$

Where $R_{S C}$ represents the short-circuit resistance; and $U_{S C}$ stands for the potential difference across the short-circuit resistance that corresponds to the potential difference between the electrodes of the PEMFC.

On the other hand, the crossover element is a mass transport element related to the following electrode reaction:

$$
\mathrm{H}_{2 \text { Cross }} \rightarrow 2 \mathrm{H}^{+}+2 e^{-}
$$

As the potential difference between the two electrodes of the PEMFC $\left(U_{\text {Cross }}\right)$ increases, the crossovered hydrogen oxidation rate also increases, resulting in a crossover oxidation current $\left(I_{\text {Cross }}\right)$ increase. An intensity plateau is reached when all the hydrogen crossovers are oxidized: a limiting current $\left(I_{\operatorname{Cross}_{L}}\right)$ is associated to this mass transport limitation. According to Faraday's law of electrolysis, in the crossover limiting current region:

$$
I_{\text {Cross }_{L}}=A \cdot n \cdot F \cdot J_{H 2 \text { Cross }}
$$

Where $A$ stands for the cell effective area; $J_{H 2}$ Cross denotes the hydrogen crossover flux; $F$ is the Faraday's constant; and $n$ is the number of exchanged electrons in the reaction ( 2 in this case). 


\subsection{Crossover diffusional model}

In this section, a mechanistic model will be presented for the hydrogen crossovers during PEMFC normal operation. In normal operation the PEMFC is fed with humidified hydrogen in the anodic compartment; and humidified air in the cathodic compartment. As mentioned in the introduction section, hydrogen crossovers from the anodic side to the cathodic side. Figure 3 illustrates the hydrogen concentration profile across the PEMFC during normal operation. An hydrogen concentration difference exists between the anodic and the cathodic compartments; and since the MEA assembly is partially permeable to hydrogen [6], a diffusive flux of hydrogen is established from the anodic to the cathodic compartment: this flux constitutes the hydrogen crossovers.

The following hypotheses are considered for the diffusional model:

$>$ Lumped model in the gas channel: reactant concentration and pressure are considered constant through all the gas channel; therefore there are no concentration gradients in the reactant flow direction;

$>$ The only considered transport phenomena is diffusion: hydrogen crosses from the anodic compartment to the cathodic one only by diffusion;

$>$ 1D diffusion: diffusion only occurs in the perpendicular to the membrane direction;

$>$ Steady-state system;

$>$ Isothermal system: all the system (both compartments) are at the same temperature;

$>$ Ideal behaviour of hydrogen in the system;

$>$ Liquid water transport phenomena interaction with hydrogen transport is not considered.

By the electrical analogy of Fick's first law, the steady state hydrogen crossover rate (the hydrogen flux) is:

$$
J_{H 2 \text { Cross }}=\frac{C_{H_{2} a}-C_{H_{2} c}}{R_{a-c}}
$$

Where $C_{H_{2} i}$ stands for the hydrogen concentration at compartment $i$ ( $a$ : anodic compartment; $c$ : cathodic compartment); $R_{a-c}$ represents the total diffusion resistance between the anodic compartment and the cathodic one.

The electrical analogous circuit to the hydrogen diffusion is shown in figure 3 . Since it consists in five resistances in series: 


$$
R_{a-c}=R_{G D L a}+R_{C L a}+R_{P E M}+R_{C L c}+R_{G D L c}
$$

Where $R_{i}$ denotes the diffusion resistance of layer $i$ (GDL: gas diffusion layer; $C L$ : catalyst layer; PEM: proton exchange membrane; $a$ : anodic compartment and $c$ cathodic compartment)

Considering the MEA assembly perfectly symmetric:

$$
R_{a-c}=2 \cdot R_{G D L}+2 \cdot R_{C L}+R_{P E M}
$$

Considering the assumed hypothesis, the different layers can be assumed to be 1D infinite parallel slabs in series. The steady state diffusion resistance for a $1 D$ diffusion wall is given by [16]:

$$
R_{i}=\frac{l_{i}}{D_{i}}
$$

Where $l_{i}$ stands for the thickness of layer $i$; and $D_{i}$ denotes the hydrogen diffusion coefficient in layer $i$.

On the one hand, the gas diffusion layer and the catalyst layer are porous layers [1].Therefore the hydrogen diffusion through these layers can be assumed to be through a porous media; and hence the hydrogen diffusion coefficient in these layers can be expressed as [16]:

$$
D_{G D L / C L}=\frac{D_{H_{2}}^{g} \cdot \varepsilon_{G D L / C L}}{\tau_{G D L / C L}}
$$

Where $D_{H_{2}}^{g}$ represents the hydrogen diffusion coefficient in gas phase; $\varepsilon_{i}$ and $\tau_{i}$ respectively stand for the porosity and the tortuosity, of layer $i$. The diffusion resistance of these porous layers can be obtained introducing (9) in (8):

$$
R_{G D L / C L}=\frac{l_{G D L / C L} \cdot \tau_{G D L / C L}}{D_{H_{2}}^{g} \cdot \varepsilon_{G D L / C L}}
$$

On the other hand, the proton exchange membrane is not a porous layer [1]. Therefore the porous media diffusion assumption cannot be applied to the PEM layer; thus the PEM layer diffusion resistance is given by: 


$$
R_{P E M}=\frac{l_{P E M}}{D_{P E M}}
$$

The literature values for the hydrogen diffusion coefficients for the operation temperature, and the properties of the different layers given by the supplier of the studied commercial PEMFC, are listed in table 1. Using these parameters and expressions (10) and (11), the values of the different diffusion resistances were estimated. The obtained values were $7.13 \mathrm{~cm}^{-1} \mathrm{~s}^{-1}$ for the gas diffusion layer diffusion resistance; $0.15 \mathrm{~cm}^{-1} \mathrm{~s}^{-1}$ for the catalyst layer diffusion resistance; and $1.83 \cdot 10^{4} \mathrm{~cm}^{-1} \mathrm{~s}^{-1}$ for the PEM layer diffusion resistance. The PEM layer diffusion resistance is several orders of magnitude greater than the other two layers diffusion resistances. Thus the diffusion limiting step is the diffusion across the polymeric membrane, and therefore the hydrogen crossover is determined by the diffusion step through the PEM layer:

$$
J_{\mathrm{H}_{2} \text { Cross }}=\frac{C_{\mathrm{H}_{2} \mathrm{Cla}}-C_{\mathrm{H}_{2} \mathrm{Clc}}}{R_{P E M}}
$$

Where $C_{\mathrm{H}_{2} \mathrm{Cli}}$ stands for the hydrogen concentration on the surface of the membrane in contact with the catalyst layer of compartment $i$.

Since the cathodic compartment is fed with an hydrogen free stream of air, it can be assumed that all the crossovered hydrogen is dragged by the air stream, and therefore, the hydrogen concentration in the cathodic compartment side can be considered negligible. Introducing this assumption in (12), and introducing the expression for the PEM layer diffusion resistance (11):

$$
J_{\mathrm{H}_{2} \text { Cross }}=\frac{D_{P E M}}{l_{P E M}} \cdot C_{\mathrm{H}_{2} \mathrm{Cla}}
$$

The transport of hydrogen across the PEM layer is done by an absorption/diffusion/desorption transport mechanism, typical for low molecular weight species transport through polymers [17]: these low molecular weight species are more or less soluble in the polymer, and therefore, are absorbed by the polymer, when they come into contact with it. Within the polymer, the species are able to diffuse into the polymer regions where the specie concentration is lower. Finally, the species are desorbed. The concentration in the surface of the polymer is related to the effective hydrogen pressure on the membrane $\left(P_{\mathrm{H}_{2}}^{*}\right)$, by the membrane's hydrogen solubility constant $\left(K_{\mathrm{H}_{2} P E M}\right)$ : 


$$
C_{H_{2} C l a}=K_{H_{2} P E M} \cdot P_{H_{2}}^{*}
$$

The permeability coefficient $\left(\psi_{H_{2}}^{P E M}\right)$ is defined as the product of the solubility constant and the diffusion coefficient, $K_{H_{2} P E M} \cdot D_{P E M}$ [17]. Replacing (14) in (13), and introducing the permeability coefficient definition:

$$
J_{H_{2} \text { Cross }}=\frac{\psi_{H_{2}}^{P E M}}{l_{P E M}} \cdot P_{H_{2}}^{*}
$$

In conclusion, according to the built diffusional crossover model, the membrane permeation coefficient is the parameter that characterizes the hydrogen crossovers; and therefore, it is the parameter that is going to be quantified and studied in the present work. 


\section{Experimental}

The experimental set up is shown in figure 4. The system's main element is a $300 \mathrm{~W}$ commercial FC stack, provided by Heliocentris, composed by 20 individual cells. Its effective area is $58 \mathrm{~cm}^{2}$ and the polymeric membrane is Nafion® ${ }^{\circledR} 117$. The PEMFC anodic compartment is fed with humidified hydrogen; whereas, humidified nitrogen is supplied to the PEMFC cathodic compartment, as shown in figure 1. Both, nitrogen and the hydrogen come from 200 bar high-pressure storage tanks. The refrigeration system consists in a heat exchanger equipped with a continuous pump and a temperature controller. The humidification system consists in two independent bubbling humidification systems, with humidification temperature control. A three way valve system allows switching from non humidification to humidification mode. The reactant gases flow rates are controlled using mass flow controllers. The reactant inlet pressures are monitored by pressure gauges and are regulated using manual valves.

The system allows to control the FC operating temperature, by the refrigeration system; and the inlet gas reactants humidities, by the humidification system. The overall control is done using a control computer with a LabVIEW ${ }^{\circledR}$ application, responsible for the system control and the data acquisition. All the experiments were carried out in open end anode mode; at the same operating temperature $\left(50^{\circ} \mathrm{C}\right)$; and with the same humidification conditions.

The linear sweep voltammetries were performed using a 4-terminal Autolab® $302 \mathrm{~N}$ potentiostat/galvanostat, controlled using NOVA® software. The tests were carried out on an individual cell of the whole commercial stack. The 2-terminal configuration is required to perform the in-situ crossover rate measurements: both the working electrode and the sensing electrode were connected to the borne of the nitrogen fed compartment; while, the counter electrode and the reference electrode were connected to the borne of the hydrogen fed compartment, as shown in figure 1 . The potential sweep was done in increasing sense, from $0.0 \mathrm{~V}$ to $0.8 \mathrm{~V}$; with a sweep speed of $1.0 \mathrm{mV} \mathrm{s}^{-1}$, since in preliminary studies it was observed that this sweep speed was slow enough to reach the steady state for each applied potential.

Since the aim of this work is to study the compartment internal pressure effect, different compartment pressures were fixed in each experiment. The internal pressure is not a directly controllable parameter in the experimental setup; but in the system the gas flow rate and the respective compartment internal pressure are correlated: so the different internal pressure values for each experiment were achieved by modifying the corresponding gas flow rate. 
Hence the actionable variable parameters in this experiment are the flow rates of the humidified hydrogen stream, and of the humidified nitrogen stream. Table 2 summarizes the flow rate values for each stream in all the performed experiments. The flow rate ranges were selected according to the normal operation flow rate ranges of the commercial system recommended by the manufacturer. The relation between the internal compartment pressures and the gas flow rates was determined in initial studies of the system. Using this relation, the compartments internal pressures for each gas flow rate (for each experiment) were determined, and are shown in table 2. The last parameter that appears in table 2 is the partial hydrogen pressure in the anodic compartment. It was calculated in previous mass balance studies of the humidification/PEMFC system. Therefore for given gas flow rates, at constant temperature and humidification conditions, the internal compartment pressures and the anodic hydrogen pressure are determined.

The startup history of a PEMFC system can heavily influence the experimental results [1]. Thus it is important to ensure that when the measurements are performed the system has already reached the steady state. In preliminary studies it was observed that letting the system work in the experiment conditions for 5 minutes, insures that the previous experiment conditions will not significantly influence the actual measurements, since the new steady state is completely reached within that lapse of time. So before each experiment, the experimental system was left for 10 minutes in the conditions of the experiment that was going to be performed. 


\section{Experimental results analysis and discussion}

\subsection{Voltammetric curves analysis}

Figure 5 shows the voltammetric curves obtained for the nitrogen high level flow rate experiments. It can be observed that all the curves have a similar shape: two linear sections with different slopes, connected by an inflexion point. Both slopes are positive; and the slope of the first stretch is higher than the second section slope. This shape is consistent with the electrical equivalent circuit proposed in figure 2 . On the one hand, for low applied potentials (first linear section), an applied potential increase causes both, the short-circuit current and the hydrogen crossover oxidation current, to increase: thus the measured current increases, leading to a positive slope in the first curve section. On the other hand, for applied potentials higher than the inflexion point potential (second linear section), an applied potential increase only causes an increase in the short-circuit current; since the limiting current for the hydrogen crossover oxidation has been reached: all the crossovered hydrogen is being oxidised, and therefore, a further increase in the driving force does not increase further the current, since the limiting step is the mass transport step. As a consequence, the slope of the second section is still positive, but is lower than the slope of the first section, because the hydrogen crossover oxidation current does not increase further. Furthermore, since the second linear section slope is only due to the internal short-circuit current and in section 2.1 a pure ohmic behaviour has been stated for the internal shortcircuits: the slope of the second linear section is the inverse of the short-circuit resistance, according to Ohm's law. Finally, the inflexion point corresponds with the point where the crossover oxidation limiting current is reached; since this is the cause of the slope change.

It can be observed in figure 5 that, for a given cathodic pressure (a given nitrogen flow rate), an increase in the anodic pressure (in the hydrogen flow rate) leads to a higher second linear section slope: an increase in the anodic pressure leads to a lower shortcircuit resistance. In addition it can be observed that, for a given cathodic pressure, the inflexion point is displaced to higher applied potentials and higher currents, with the anodic pressure increase: an increase in the anodic pressure leads to a higher limiting current, and therefore to a higher hydrogen crossover flux. The same trends are observed for the nitrogen low level flow rate experiments.

\subsection{Internal short-circuit currents}

Although clear qualitative conclusions can be extracted from voltammetric curves, a further curve processing must be done in order to be able to extract quantitative conclusions. Each voltammetric curve processing was done in two steps. Firstly, the 
short-circuit resistance for the analyzed experiment conditions was determined. As it was stated previously, the short-circuit resistance matches with the inverse of the slope of the second curve stretch. Therefore, the second linear section was fitted to a linear model using the least squares method; and the resistance was quantified as the inverse of the slope of the fitted linear model. The determined short-circuit resistances for each experiment are represented in figure 6 . With this resistance parameter the internal short-circuit is fully characterized.

In figure 6, two clear trends can be observed: an increase in the anodic pressure results in the decrease of the internal short-circuit resistance; whereas an increase in the cathodic pressure leads to an increase of the short-circuit resistance. A statistical analysis was performed on the short-circuit resistance results to check if the graphically observed tendencies were statistically significant: an analysis of the variance (ANOVA) study was done, taking as dependant parameter the short-circuit resistance; and as independent factors the anodic and the cathodic pressures. ANOVA is a well established statistical method, which is deeply explained in any statistics book [19]. The results of the ANOVA analysis are presented in table 3 . The p-values associated to both factors are lower than 0.05; therefore both factors have a statistically significant effect on the short-circuit resistance, with a $95 \%$ confidence level: both compartment pressures have significant statistical effects on the internal short-circuit resistance. Therefore, in the studied pressure range, the anodic pressure has a significant negative effect on the short-circuit resistance; whereas the cathodic pressure has a significant positive effect.

No previous studies on the effect of pressure on the short-circuit resistance are available in literature. However, several studies of the effect of the clamping pressure on the contact resistance between the bipolar plates and the gas diffusion layers exist [20]. According to these studies, an increase of the clamping pressure has two distinct effects on the contact resistance. On the one hand, an increase in the clamping pressure causes an increase in the interfacial effective contact area between the surfaces in contact [21], causing a decrease in the contact resistance. On the other hand, an increase in the clamping pressure causes changes in the porosity and morphology of the catalyst and diffusion layers [22], which may result in an increase or a decrease of the contact resistance, depending on the particular structural characteristics of the system [23].

The short-circuit resistance can be assumed to behave as a contact resistance. Therefore, it can be assumed that the gas pressure acts on the short-circuit resistance in an analogous manner to the way the clamping pressure acts on the overall contact resistance; since it is a pressure that acts on the MEA assembly, just as the clamping pressure. Obviously, the gas pressure will only act on the MEA exposed portion to the 
bulk gas flow: the distribution channels. But certainly, changes in the anodic and the cathodic pressures will have the same effects (but smaller, since the variation range of the gas pressure is lower than the variation range in clamping pressure) that the changes in the clamping pressure, discussed above.

In short, for the present work it is assumed that the internal short-circuit resistance variations due to anodic and cathodic pressure variations are due to the changes in the contact resistances between the different MEA layers. And such contact resistances vary with the gas pressure due to the same phenomenons that cause the contact resistance variations due to clamping pressure modification, but in a smaller range. On one hand, an increase of the gas pressure causes an increase in the effective interfacial contact area between the different layers, resulting in a decrease of the short-circuit resistance. On the other hand, an increase of the gas pressure causes porosity and morphological changes in the catalyst and diffusion layers, that can lead to an increase or a decrease of the short-circuit resistance depending on the particular characteristics of the PEMFC. Depending of the effect sign of the second phenomenon, and the relative importance of the two phenomena, an increase in the anodic or the cathodic internal pressure may results in either an increase or a decrease in the short-circuit resistance. However this is only a possible hypothesis that explains the observed experimental data: further work should be done in order to ascertain the stated hypothesis.

The above model is consistent with the obtained experimental results. For the examined pressure range, and the particular configuration of the studied commercial PEMFC: an increase in the anodic pressure results in a decrease of the short-circuit resistance; while an increase in the cathodic pressure leads to an increase in the shortcircuit resistance. Therefore, for the studied commercial cell and the considered pressure range: in the anodic compartment, the first phenomenon (effective contact area increase) prevails, or the second phenomenon (porosity and morphological changes) has a negative effect due to the particular structural characteristics of the commercial PEMFC; whereas, in the cathodic compartment the second phenomenon is predominant, and due to the structural characteristics of the commercial PEMFC, it has a positive effect on the short-circuit resistance. Certainly, these conclusions may change in other pressure ranges, and for other cells with different structural characteristics.

The mechanistic modelling of these phenomenons is very complicated, due to the large amount of involved factors [20]. Mishra proposed a semi-empirical model for the effect of the clamping pressure on the contact resistance [24]:

$$
R=A \cdot B^{C} \cdot P^{-C}
$$


Where $R$ stands for the contact resistance; $P$ denotes the clamping pressure; and $A, B, C$ are parameters, determined experimentally, that arise from a mechanistic study of the two phenomenons discussed previously.

Following with the proposed analogy between the gas pressure/short-circuit resistance and the clamping pressure/contact resistance, the following model, based on Mishra's model, is proposed in the present work to reproduce the effect of the compartment pressures on the short-circuit resistance:

$$
R_{S C}=\alpha \cdot P_{a}^{-\theta_{a}} \cdot P_{c}^{-\theta_{c}}
$$

Where $\alpha, \theta_{a}, \theta_{c}$ are the model parameters, equivalent to the $A, B, C$ parameters of the Mishra's model.

Using the least squares fitting method, the above model was adjusted to the experimental points, obtaining:

$$
R_{S C}(\Omega)=3.09 \cdot P_{a}(a t m)^{-9.63} \cdot P_{c}(a t m)^{0.38}
$$

The model predictions are represented in figure 6 . It can be observed that the model is able to properly reproduce the trend of the experimental point cloud; and conveniently fits the experimental points, as evidenced by a determination coefficient of $94.36 \%$. Therefore, the proposed model can be considered to model properly the experimental behaviour of the commercial PEMFC short-circuit resistance in the considered pressure range.

Note that the exponential term associated to the anodic pressure is negative; while the exponential term associated to the cathodic pressure is positive: an increase in the anodic pressure term leads to a drop in the short-circuit resistance; whereas, an increase in the cathodic pressure term leads to a rise of the short-circuit resistance. It can also be observed that the absolute value of the exponential term associated to the anodic pressure is an order of magnitude bigger than the cathodic exponential term: the short-circuit resistance is more sensitive to anodic pressure variations, than to cathodic pressure variations. All these model-derived observations are consistent with the observed experimental behaviour of the commercial PEMFC.

\subsection{Hydrogen crossovers}

Secondly, the hydrogen crossovers were characterized. The first step to characterize the crossovers is to determine the limiting oxidation current contribution for each 
applied potential. As it was explained in section 2.1, the total measured current has two contributions: the short-circuit current (with an ohmic behavior) and the crossover oxidation current. Therefore, since both currents (the measured current and the shortcircuit current) are known, they can be used to calculate the crossover oxidation current for each experimental point. Combining (1) and (2):

$$
I_{\text {Cross }}=I-\frac{U_{P}}{R_{S C}}
$$

Where $I$ and $U_{P}$ are the measured current and the applied potential respectively, that are represented in the voltammetric curves. So expression (19) was used for each experimental point to determine the crossover oxidation current contribution for that point. By this method, the crossover oxidation current for each applied potential was determined, obtaining the crossover oxidation current plots, shown in figure 7 for the high nitrogen flow rate experiments. It can be observed that the crossover oxidation current curves show the typical mass transport limited current pattern: the limiting current can be determined as the asymptotic value of the curve. A clear trend can be recognised in figure 7: for higher hydrogen flow rates (higher anodic pressure) the crossover oxidation limiting current is higher; which implies that the hydrogen crossover flux is higher, according to expression (4). This observation is consistent with the diffusion model presented in section 2.2.

The low nitrogen flow rate experiment curves show the same trend. Figure 8 shows

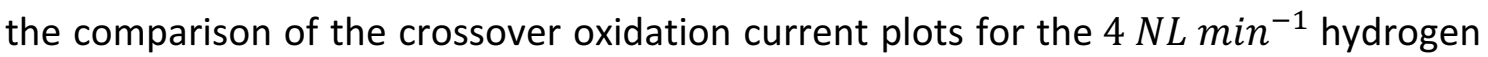
flow rate experiments, for both nitrogen flow rates. No discernable effect of the nitrogen flow rate (cathodic total pressure) on the limiting current (and thus on the hydrogen crossovers) can be observed neither in figure 8 , nor in the comparison of the curves obtained for both nitrogen flow rates for the rest of hydrogen flow rates. The fact that the cathodic pressure does not have a significant effect on the hydrogen crossover confirms the pure diffusion transport hypothesis considered to build the diffusion model presented in section 2.2.

The limiting current for each experiment was determined from the asymptotic value of its corresponding hydrogen crossover oxidation curve. In parallel, for validation purposes, the inflection point current, which is related with the mass transport limiting current, was determined directly from voltammetric curves using the Cowan-Brown method [25]. Figure 9 shows the application of the Cowan-Brown method to determine the inflexion point current, $I_{L}{ }^{*}$, from which the crossover oxidation limiting current can be obtained by subtraction of the short-circuit current. 
Expression (4) gives the relation between the mass transport limiting current and the hydrogen crossover flux. Clearing the crossover flux yields to the following expression:

$$
J_{H 2 \text { Cross }}=\frac{I_{\operatorname{Cross}_{L}}}{A \cdot n \cdot F}
$$

The limiting current value obtained from each crossover oxidation current curve was introduced in the above expression, in order to obtain the hydrogen crossover flux for each experiment. The obtained hydrogen crossover fluxes for the different internal pressures are represented in figure 10 versus the anodic hydrogen partial pressure, since it was introduced in section 2.2 the hydrogen anodic partial pressure is the significant pressure factor for the hydrogen crossovers.

Figure 10 shows a clear trend in the hydrogen crossover flux with the anodic hydrogen partial pressure: an increase in the hydrogen partial pressure results in an increase in the hydrogen crossover flux. This is consistent with the observations extracted from the hydrogen crossovers oxidation current curves. Furthermore, a linear trend is observed: the hydrogen crossover flux seems to increase linearly with the anodic hydrogen partial pressure.

Finally, according to the built diffusion model, the membrane hydrogen permeability constant is related to the hydrogen crossover flux by expression (15), rearranging it:

$$
\psi_{H_{2}}^{\text {PEM }}=\frac{J_{H_{2} \text { Cross }} \cdot l_{\text {PEM }}}{P_{H_{2}}^{*}}
$$

The membrane thickness value was supplied by the membrane supplier: the Nafion ${ }^{\circledR}$ 117 membrane thickness is $183 \mu \mathrm{m}$. Introducing this value, the calculated crossover flux and the anodic hydrogen partial pressure for each experiment, in expression (21) the value of the membrane permeability constant was determined. The obtained values for each experiment are shown in figure 11.

No distinguishable patterns appear in the representation of the membrane permeation coefficient versus the hydrogen partial pressure, shown in figure 11. A proper statistical study was performed in order to quantify the effect of the hydrogen partial pressure and the cathodic pressure on the membrane permeation coefficient: an ANOVA study was done, taking as dependant parameter the hydrogen permeation coefficient; and as independent factors the anodic hydrogen partial pressure and the cathodic pressure. The results of the ANOVA analysis are presented in table 4 . The $p$ values associated to both factors are higher than 0.05 ; therefore both factors have no statistically significant effect on the permeation coefficient, with a $95 \%$ confidence level: neither the hydrogen partial pressure nor the cathodic pressure have a 
statistically significant effect on the permeation coefficient. Therefore the membrane permeation coefficient variations that appear in figure 11 can be attributed to measurement uncertainties; and the membrane permeation coefficient can be considered constant with both, the anodic hydrogen partial pressure and the cathodic pressure.

As it was stated in section 2.2, the permeation coefficient is the product of the solubility coefficient and the diffusion coefficient. On the one hand, the hydrogen diffusion coefficient in Nafion $®$ is virtually constant with pressure [13]. On the other hand, the hydrogen solubility coefficient in Nafion ${ }^{\circledR}$ membranes shows a similar tendency to the hydrogen solubility coefficient in water [9]; and the hydrogen solubility coefficient remains constant with pressure, for pressures under $100 \mathrm{~atm}$ [26]. Therefore, since the studied pressure range is markedly under $100 \mathrm{~atm}$, it can be deduced that the pressure (in the studied pressure range) has a negligible effect on the hydrogen solubility constant of the Nafion $®$ membrane. As a result, since both, the solubility and the diffusion coefficients, are constant with pressure, in the studied pressure range, the permeation coefficient will also be constant [27]. This matches with the results of the statistical study, according to which neither the anodic nor the cathodic pressures had a significant effect on the permeation coefficient.

Thus, the permeation coefficient was considered constant and equal to the mean of the permeation coefficient values determined for each experiment:

$$
\psi_{H_{2}}^{P E M}=9.98 \cdot 10^{-9} \frac{\text { mol }}{\text { matms }}
$$

This outcome is consistent with the values of hydrogen permeation coefficient in wet Nafion $®$ membranes reported in literature: the hydrogen permeation coefficient is in the range $10^{-8}-10^{-9} \frac{\mathrm{mol}}{\mathrm{matm}}$, for a temperature range of $15^{\circ} \mathrm{C}-85^{\circ} \mathrm{C}$ [5].

The result that the permeation coefficient is constant with pressure corroborates the fact that crossover flux varies linearly with the hydrogen partial pressure, as it was observed in figure 10. Furthermore, the fact that the cathodic pressure has no significant effect on the hydrogen crossover flux validates the pure diffusive crossover model. 


\section{$\underline{\text { 5. Conclusions }}$}

In conclusion, the proposed methodology makes possible to analyze both, the hydrogen crossovers and the internal short-circuit current, two of the three phenomena that lead to open circuit losses in PEMFC.

On the one hand, the internal short-circuit resistance increases with cathodic pressure and drops with the anodic one. An analogy between the clamping pressure/contact resistance and gas pressure/short-circuit resistance was proposed, and successfully explained the experimental tendencies of the short-circuit resistance with pressure. A potential model, based on the previous analogy, was built. The model was able to satisfactorily represent the experimental behaviour of the internal short-circuit resistance.

On the other hand, the hydrogen crossover flux increases linearly with the anodic hydrogen partial pressure, and is not sensible to cathodic pressure variations. A pure diffusive model was used successfully to model the experimental crossover behaviour; deducing the membrane's permeation coefficient, which was found to remain constant with pressure, in the studied pressure range. 


\section{Nomenclature}

\section{Normal letters}

$\begin{array}{ll}A & \text { Cell effective area }\left(\mathrm{m}^{2}\right) \\ C_{\mathrm{H}_{2} i} & \text { Hydrogen concentration in the surface of layer } \mathrm{i}\left(\mathrm{mol} \mathrm{m} \mathrm{m}^{-3}\right) \\ D_{i} & \text { Hydrogen diffusion coefficient in layer } i\left(\mathrm{~m}^{2} \mathrm{~s}^{-1}\right) \\ D_{\mathrm{H}_{2}}^{g} & \text { Hydrogen diffusion coefficient in gas phase }\left(\mathrm{m}^{2} \mathrm{~s}^{-1}\right) \\ F & \text { Faraday's constant }\left(\mathrm{C} \mathrm{mol}^{-1}\right) \\ I & \text { Electric total current }(A) \\ I_{\text {Cross }} & \text { Crossover oxidation electric current }(A) \\ I_{\text {Cross }} & \text { Crossover oxidation limiting current }(A) \\ I_{S C} & \text { Internal short-circuit electric current }(A) \\ J_{H 2} \text { Cross } & \text { Hydrogen crossover flux }\left(\mathrm{mol} \mathrm{m}^{-2} \mathrm{~s}^{-1}\right) \\ K_{\mathrm{H}_{2} P E M} & \text { Hydrogen solubility constant in the membrane }\left(\mathrm{mol} \mathrm{m}^{-3} \mathrm{~Pa}^{-1}\right) \\ l_{i} & \text { Layer } i \text { thickness }(\mathrm{m}) \\ n & \text { Exchanged number of electrons } \\ P_{i} & \text { Total internal pressure of compartment } i(\mathrm{~Pa}) \\ P_{H_{2}}^{*} & \text { Hydrogen effective pressure on the membrane anodic side }(\mathrm{Pa}) \\ R_{i-j} & \text { Diffusion resistance between point } i \text { and pint j }\left(\mathrm{m}^{-1} \mathrm{~S}^{-1}\right) \\ R_{S C} & \text { Short-circuit resistance }(\Omega) \\ U_{P} & \text { Applied potential difference }(\mathrm{V}) \\ U_{S C} & \text { Potential difference across the short-circuit resistance }(\mathrm{V})\end{array}$

\section{Greek letters}

$\begin{array}{ll}\varepsilon_{i} & \text { Porosity of layer } i \\ \tau_{i} & \text { Tortuosity of layer } i \\ \psi_{\mathrm{H}_{2}}^{P E M} & \text { Membrane hydrogen permeability constant }\left(\mathrm{mol} \mathrm{m}^{-1} \mathrm{~Pa}^{-1} \mathrm{~s}^{-1}\right)\end{array}$

\section{Subscripts}

$\begin{array}{ll}a & \text { Anodic } \\ c & \text { Cathodic } \\ C L & \text { Catalyst layer } \\ \text { Cross: } & \text { Crossover } \\ G D L & \text { Gas diffusion layer } \\ P E M & \text { Proton exchange membrane } \\ S C & \text { Short-circuit }\end{array}$




\section{Acknowledgments}

The authors are very grateful to the Generalitat Valenciana for its economic support in form of Vali+d grant (Ref: ACIF-2013-268). 


\section{References}

[1] Barbir F. PEM fuel cells. London: Elsevier Academic Press; 2005.

[2] Larminie J, Dicks A. Fuel cell systems explained. 2nd ed. Chichester England: John Wiley \& Sons; 2003.

[3] Chen E. Fuel cell technology handbook. London: CRC press; 2003.

[4] Zhang J, Tang Y, Song C, Zhang J, Wang H. PEM fuel cell open circuit voltage (OCV) in the temperature range of $23^{\circ} \mathrm{C}$ to $120^{\circ} \mathrm{C}$. J Power Sources 2006; 163: 532-7.

[5] Kocha S, Yang JD, Yi JS. Characterization of gas crossover and its implications in PEM fuel cells. AIChE J 2006; 52: 1916-25.

[6] Cheng $X$, Zhang J, Tang $Y$, Song $C$, Shen J, Song D, Zhang J. Hydrogen crossover in high-temperature PEM fuel cells. J Power Sources 2007; 167: 25-31.

[7] Spiegel C. PEM fuel cell modelling and simulation using Mathlab. San Diego: Elsevier; 2008.

[8] Mann RF, Amphlett JC, Hooper Al, Jensen HM, Peppley BA, Roberge PR. Development and application of a generalized steady-state electrochemical model for a PEM fuel cell. J Power Sources 2000; 86: 173-80.

[9] Mann RF, Amphlett JC, Peppley BA, Thurgood CP. Henry's law and the solubilities of reactant gases in the modeling of PEM fuel cells. J Power Sources 2006; 161: 768-74.

[10] LaConti $A B$, Fragala $A R$, Boyack JR. Electrode materials and processes for energy conversion and storage. Pennington: The Electrochemical Society; 1977, p. 354-374.

[11] Sakai T, Takenata H, Wakabayashi N, Kawani Y, Torikai E. Gas permeation properties of solid polymer electrolyte membranes. J Electrochem Soc 1985; 132: 1328-32.

[12] Sakai T, Takenata H, Torikai E. Gas diffusion in the dried and hydrated Nafions. J Electrochem Soc 1986; 133: 88-92.

[13] Chiou JS, Paul DR. Gas permeation in a dry Nafion membrane. Ind Eng Chem Res 1988; 27: 2161-4. 
[14] Broka K, Ekdunge P. Oxygen and hydrogen permeation properties and water uptake of Nafion 117 membrane and recast film for PEM fuel cell. J Appl Electrochem 1997; 27: 117-23.

[15] Zhang S, Yuan X, Wang H. PEM fuel cell diagnostic tools. London: CRC Press; 2012, p. 87-100.

[16] Cengel YA. Heat and mass transfer: a practical approach. 3rd ed. Boston: McGrawHill; 2007.

[17] Van der Begt A. From polymers to plastics. Delft : Delft University Press; 2002.

[18] West AC, Fuller TF. Influence of rib spacing in proton-exchange membrane electrode assemblies. J Appl Electrochem 1996; 26: 557-65.

[19] Montgomery DC. Design and analysis of experiments. 7th ed. London: John Wiley \& Sons; 2009.

[20] Lai X, Liu D, Peng L, Ni J. A mechanical-electrical finite element method for predicting contact resistance between bipolar plate and gas diffusion layer in PEM fuel cells. J Power Sources 2008; 182: 153-9.

[21] Zhang L, Liu Y, Song H, Wang S., Zhou Y. Estimation of contact resistance in proton exchange membrane fuel cells. J Power Sources 2006; 162: 1165-71.

[22] Zhou Y, Lin G, Shih AJ, Hu SJ. Assembly pressure and membrane swelling in PEM fuel cells. J Power Sources 2009; 192: 544-51.

[23] Wu Z, Zhou Y, Lin G, Wang S, and Hu SJ. An improved model for predicting electrical contact resistenace between bipolar plate and gas diffusion layer in proton exchange membrane fuel cells. J Power Sources 2008; 182: 265-9.

[24] Mishra V, Yang F, Pitchumani R. Measurement and prediction of electrical contact resistance between gas diffusion layers and bipolar plate for applications to PEM fuel cells. J Fuel Cell Sci Tech 2004; 1: 2-9.

[25] Rapp HJ, Pfromm PH. Electrodialysis for chloride removal from the chemical recovery cycle of a Kraft pulp mill. J Membrane Sci 1998; 146: 249-61.

[26] Wiebe R, Gaddy VL, Heins C. Solubility of hydrogen in water at 25ㅇ C from 25 to 1000 atmospheres. Ind Eng Chem 1932; 24: 823-25. 
[27] Ito $\mathrm{H}$, Maeda T, Nakano A, Takenaka H. Properties of Nafion membranes under PEM water electrolysis conditions. Int J Hydrogen Energ 2011; 36: 10527-40. 
LIST OF TABLES.

Table 1. Diffusion resistance parameter values

Table 2. Experiment parameters

Table 3. ANOVA table for the short-circuit resistance

Table 4. ANOVA table for the permeation coefficient 
LIST OF FIGURES.

Figure 1. In-situ linear sweep voltammetry method. (WE: working electrode; R: reference electrode; C: counter electrode)

Figure 2. Proposed electrical equivalent circuit for the experimental system operation

Figure 3. Diffusion resistances for hydrogen crossover through a PEMFC in normal

Figure 4. Experimental setup

Figure 5. Voltammetry sweep results for the high nitrogen flow rate experiments

Figure 6. Internal short-circuit resistance change with compartment internal pressures

Figure 7. Hydrogen crossovers oxidation currents for the high nitrogen flow rate experiments

Figure 8. Hydrogen crossovers oxidation currents for the $4 \mathbf{N L} \cdot \min ^{-1}$ hydrogen flow rate experiments

Figure 9. Cowan-Brown method for inflexion point determination

Figure 10. Hydrogen crossover flux variation with the anodic hydrogen partial pressure

Figure 11. Membrane permeation coefficient variation with the anodic hydrogen partial pressure 
Table 1. Diffusion resistance parameter values

\begin{tabular}{ccc} 
Parameter & Value & Reference \\
\hline $\boldsymbol{D}_{\boldsymbol{H}_{2}}^{g}$ & $2.63 \cdot 10^{-2} \mathrm{~cm}^{2} \mathrm{~s}^{-1}$ & {$[18]$} \\
$\boldsymbol{l}_{\boldsymbol{G D L}}$ & $500 \mu \mathrm{m}$ & Supplier \\
$\boldsymbol{\varepsilon}_{\boldsymbol{G D L}}$ & 0.40 & Supplier \\
$\boldsymbol{\tau}_{\boldsymbol{G D L}}$ & 1.50 & Supplier \\
$\boldsymbol{l}_{\boldsymbol{C L}}$ & $10 \mu \mathrm{m}$ & Supplier \\
$\boldsymbol{\varepsilon}_{\boldsymbol{C L}}$ & 0.25 & Supplier \\
$\boldsymbol{\tau}_{\boldsymbol{C L}}$ & 1.00 & Supplier \\
$\boldsymbol{D}_{\boldsymbol{P E M}}$ & $10^{-6} \mathrm{~cm}^{2} \mathrm{~s}^{-1}$ & {$[6]$} \\
$\boldsymbol{l}_{\boldsymbol{P E M}}$ & $183 \mu \mathrm{m}$ & Supplier
\end{tabular}


Table 2. Experiment parameters

\begin{tabular}{|c|c|c|c|c|c|c|}
\hline & Experiment & $Q_{\mathrm{H}_{2}}(\mathrm{Nl} / \mathrm{min})$ & $Q_{N_{2}}(N l / \mathrm{min})$ & $P_{c}(P a)$ & $P_{a}(P a)$ & $P_{\mathrm{H}_{2}}^{*}(\mathrm{~Pa})$ \\
\hline \multirow{4}{*}{ 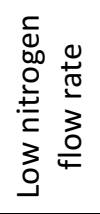 } & Experiment 1 & 2 & 15 & 111979 & 101021 & 53743 \\
\hline & Experiment 2 & 4 & 15 & 111979 & 102591 & 71198 \\
\hline & Experiment 3 & 6 & 15 & 111979 & 104162 & 80517 \\
\hline & Experiment 4 & 8 & 15 & 111979 & 105732 & 86594 \\
\hline \multirow{4}{*}{ 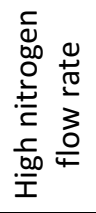 } & Experiment 5 & 2 & 35 & 144954 & 101021 & 53743 \\
\hline & Experiment 6 & 4 & 35 & 144954 & 102591 & 71198 \\
\hline & Experiment 7 & 6 & 35 & 144954 & 104162 & 80517 \\
\hline & Experiment 8 & 8 & 35 & 144954 & 105732 & 86594 \\
\hline
\end{tabular}


Table 3. ANOVA table for the short-circuit resistance

\begin{tabular}{cccccc} 
Factor & $\begin{array}{c}\text { Sum of } \\
\text { squares }\end{array}$ & $\begin{array}{c}\text { Degrees of } \\
\text { freedom }\end{array}$ & $\begin{array}{c}\text { Mean } \\
\text { square }\end{array}$ & F ratio & p-value \\
\hline $\boldsymbol{P}_{\boldsymbol{a}}$ & 1.8322 & 3 & 0.6107 & 45.70 & 0.0053 \\
$\boldsymbol{P}_{\boldsymbol{c}}$ & 0.1863 & 1 & 0.1863 & 13.94 & 0.0335 \\
Residual & 0.0401 & 3 & 0.0134 & & \\
Total & 2.0586 & 7 & & &
\end{tabular}


Table 4. ANOVA table for the permeation coefficient

\begin{tabular}{cccccc} 
Factor & $\begin{array}{c}\text { Sum of } \\
\text { squares }\end{array}$ & $\begin{array}{c}\text { Degrees of } \\
\text { freedom }\end{array}$ & $\begin{array}{c}\text { Mean } \\
\text { square }\end{array}$ & F ratio & p-value \\
\hline $\boldsymbol{P}_{\boldsymbol{H} 2}$ & $3.87 \cdot 10^{-12}$ & 3 & $1.29 \cdot 10^{-12}$ & 1.70 & 0.3372 \\
$\boldsymbol{P}_{\boldsymbol{c}}$ & $5.91 \cdot 10^{-13}$ & 1 & $5.91 \cdot 10^{-13}$ & 0.78 & 0.4430 \\
Residual & $2.28 \cdot 10^{-12}$ & 3 & $7.76 \cdot 10^{-13}$ & & \\
Total & $6.75 \cdot 10^{-12}$ & 7 & & &
\end{tabular}




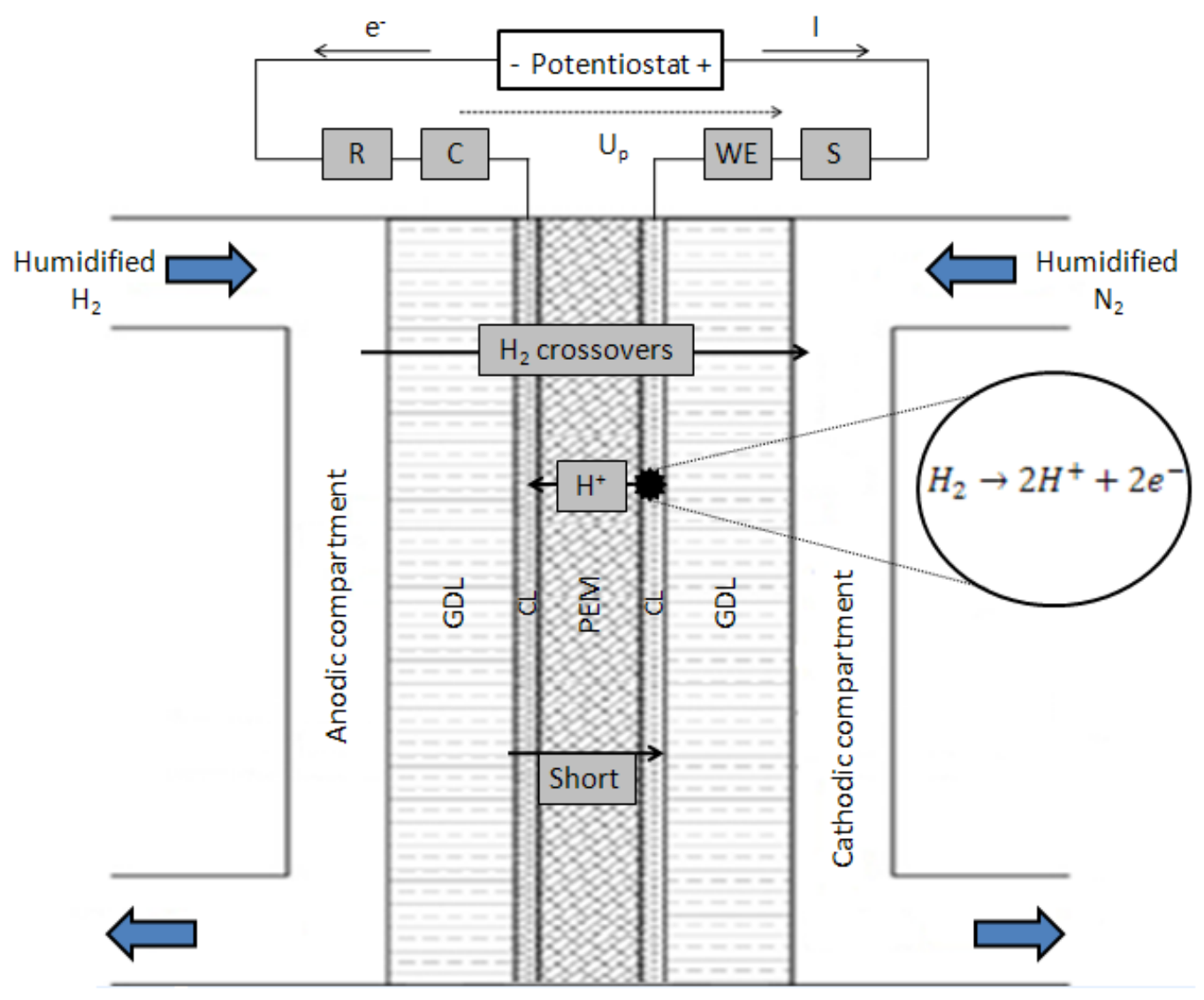

Figure 1. In-situ linear sweep voltammetry method (WE: working electrode; R: reference electrode; C: counter electrode) 


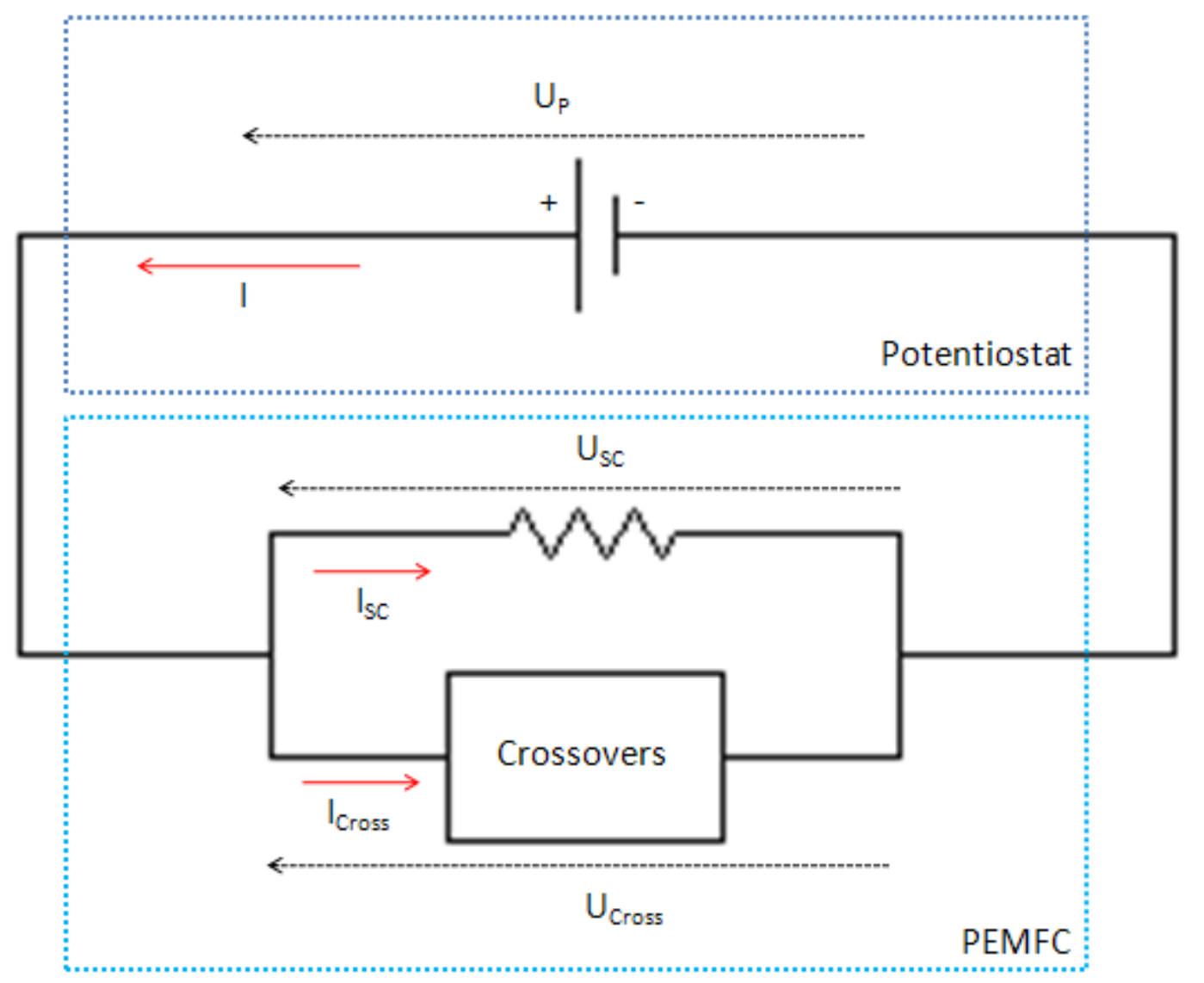

Figure 2. Proposed electrical equivalent circuit for the experimental system 


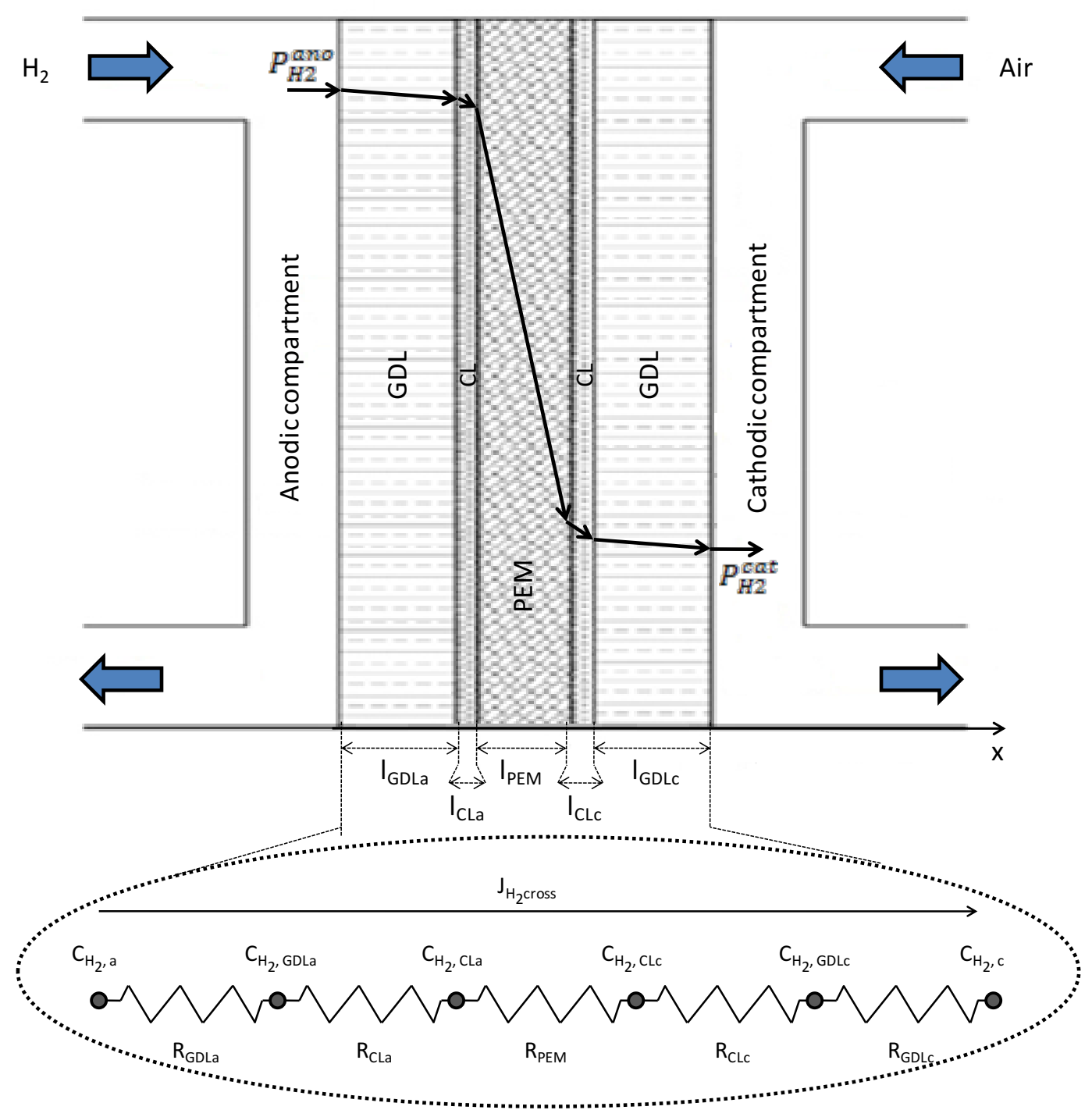

Figure 3. Diffusion resistances for hydrogen crossover through a PEMFC in normal operation 


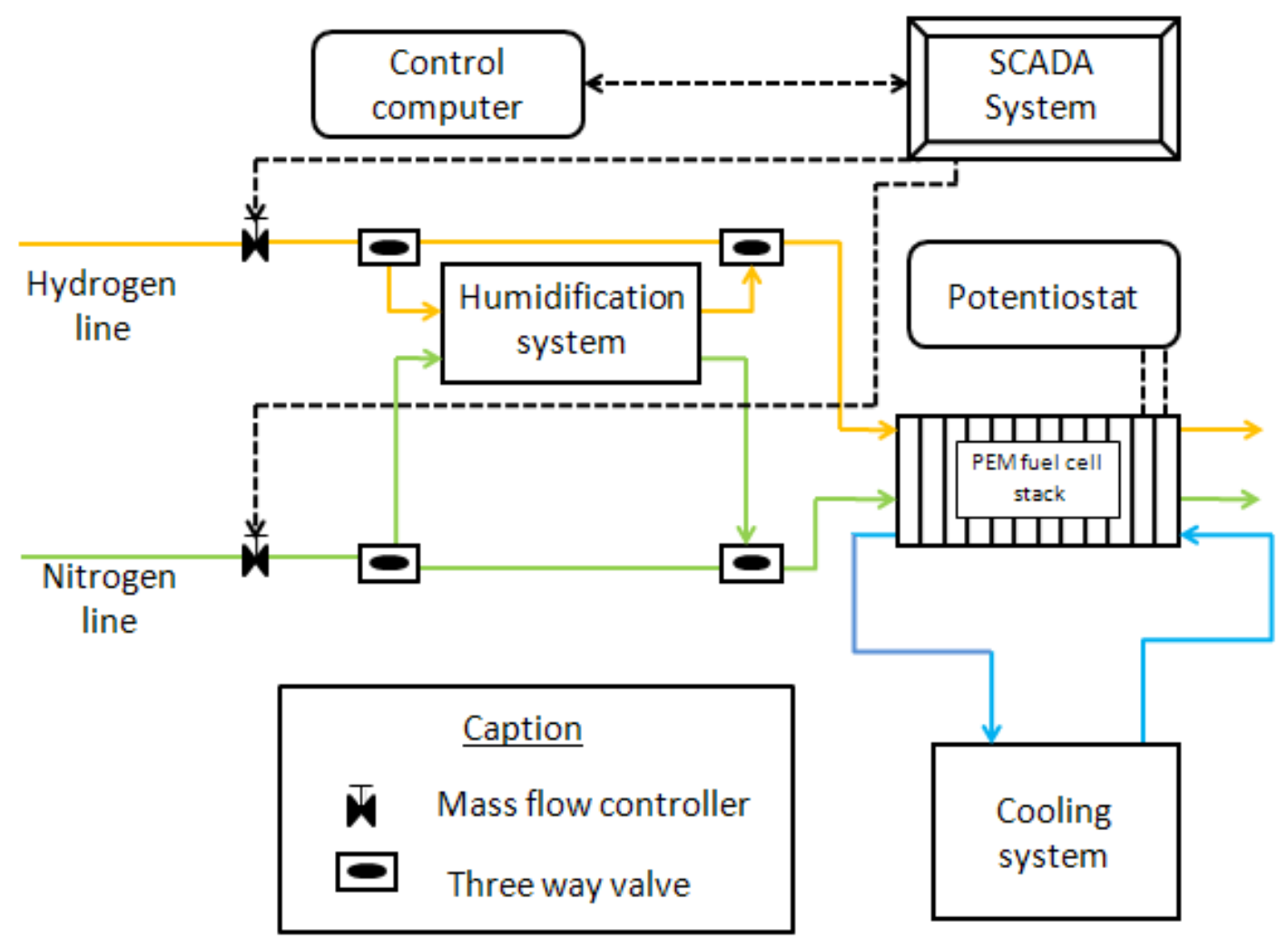

Figure 4. Experimental setup 


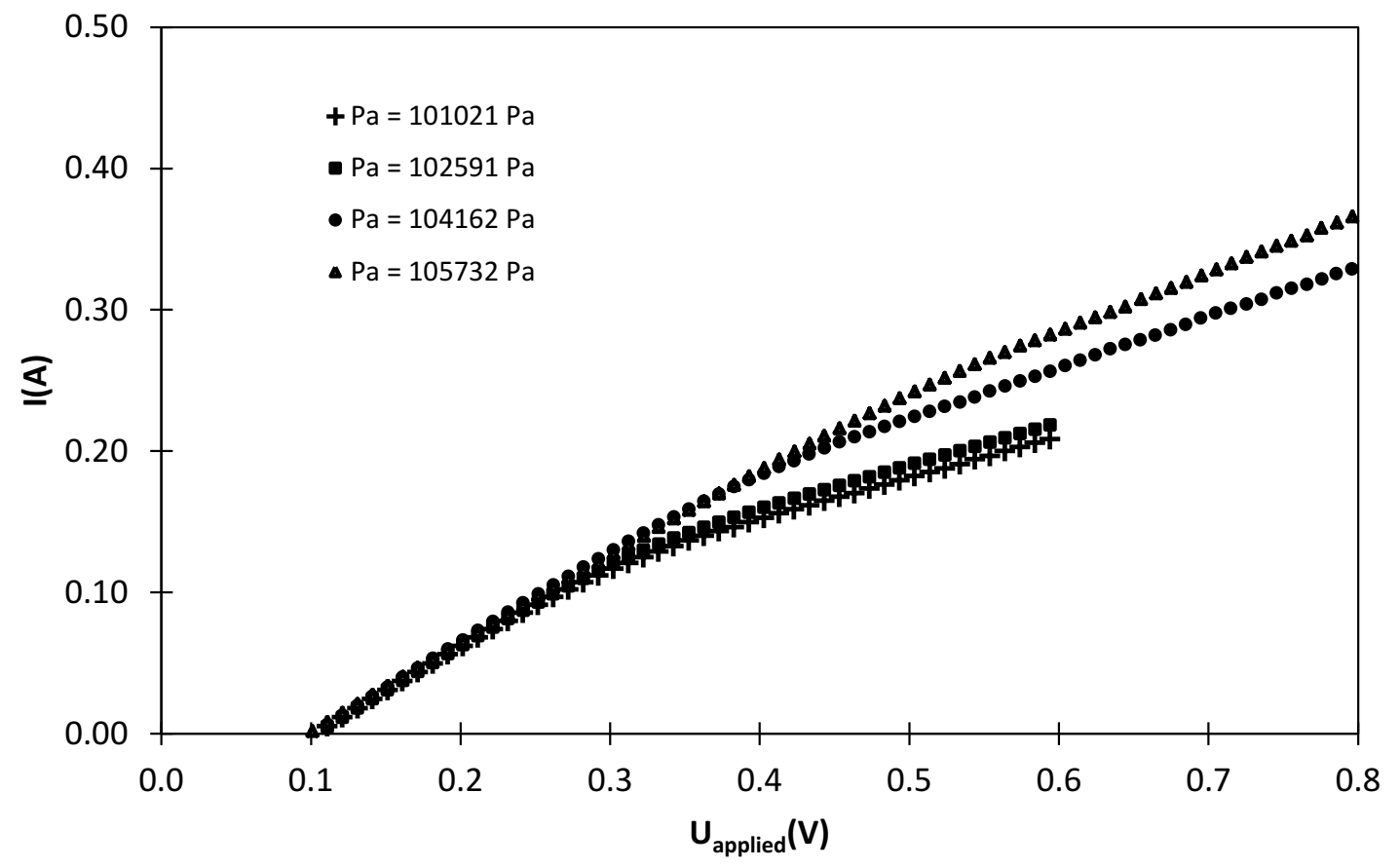

Figure 5. Voltammetry sweep results for the high nitrogen flow rate experiments 


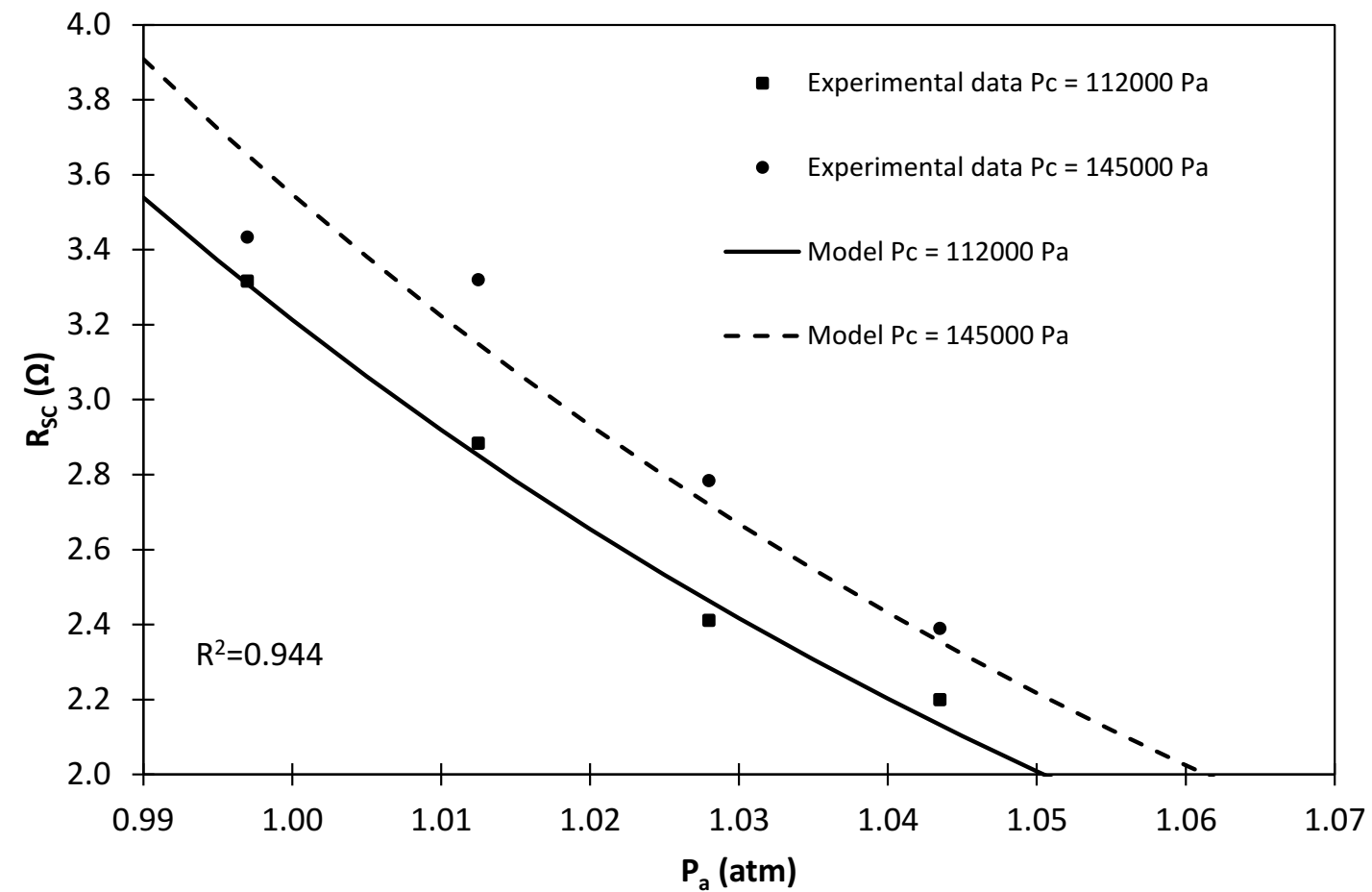

Figure 6. Internal short-circuit resistance change with compartment internal pressures 


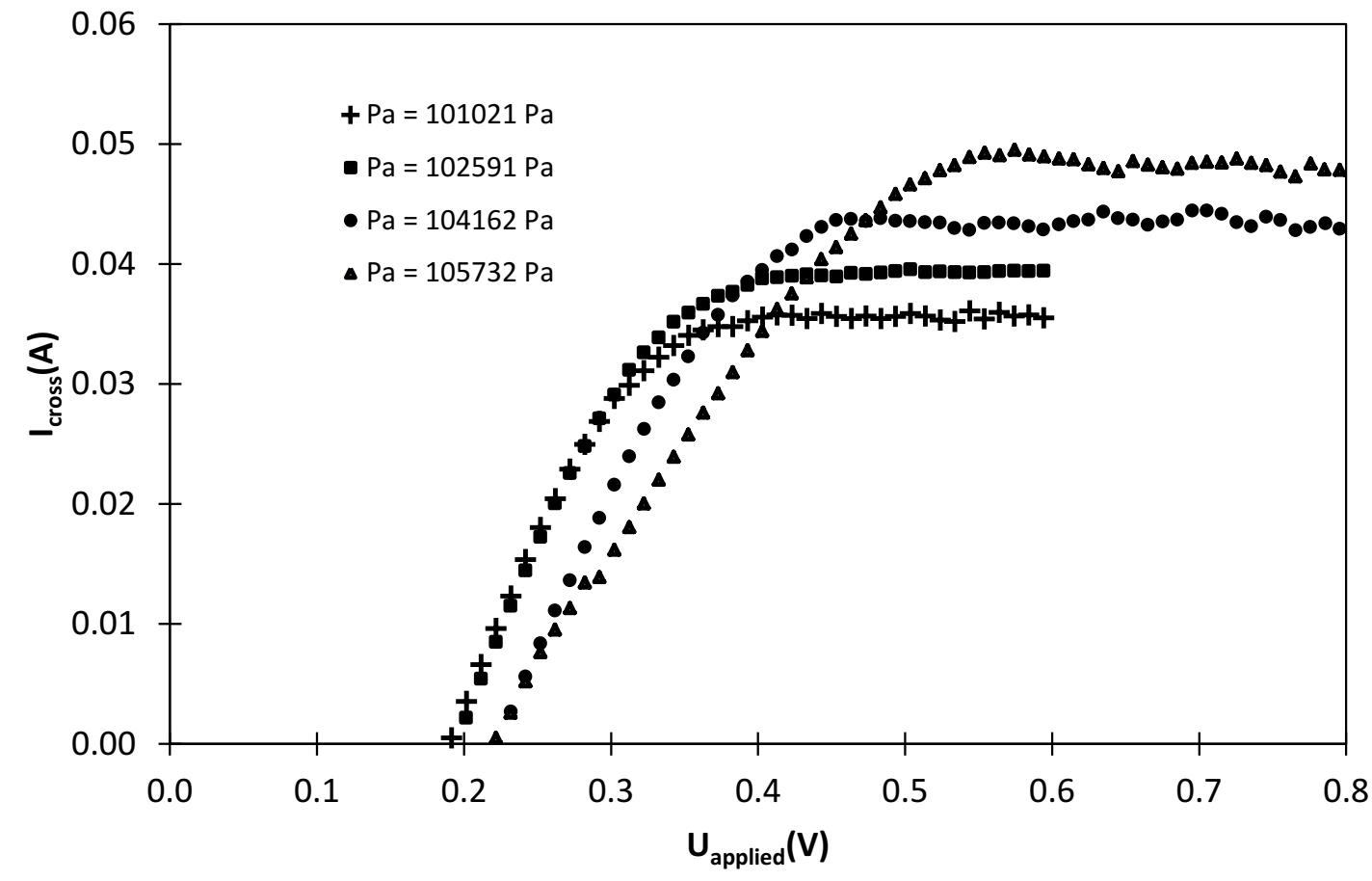

Figure 7. Hydrogen crossovers oxidation currents for the high nitrogen flow rate experiments 


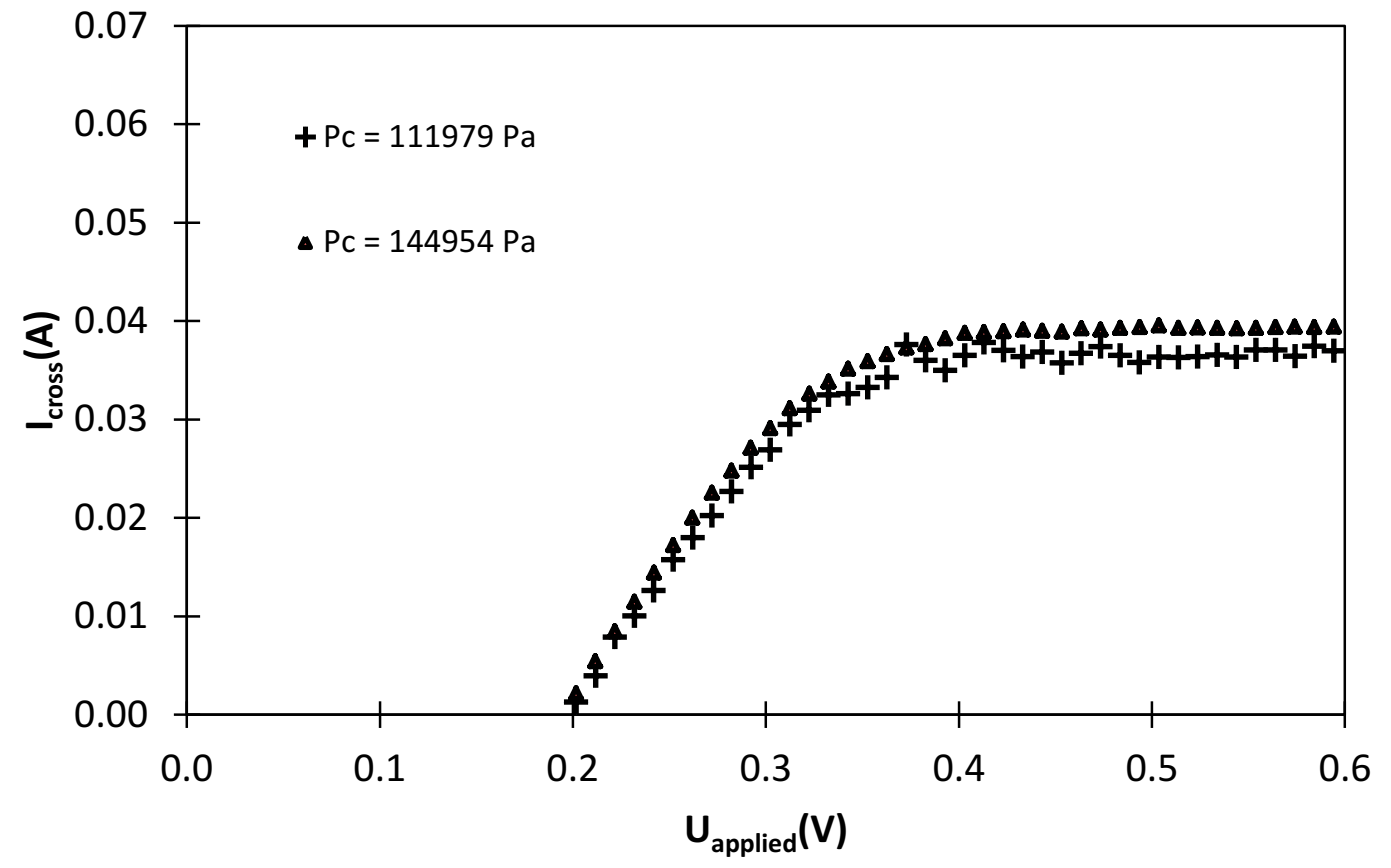

Figure 8. Hydrogen crossovers oxidation currents for the $\mathbf{4} \mathbf{N} \cdot \min ^{-1}$ hydrogen flow rate experiments 


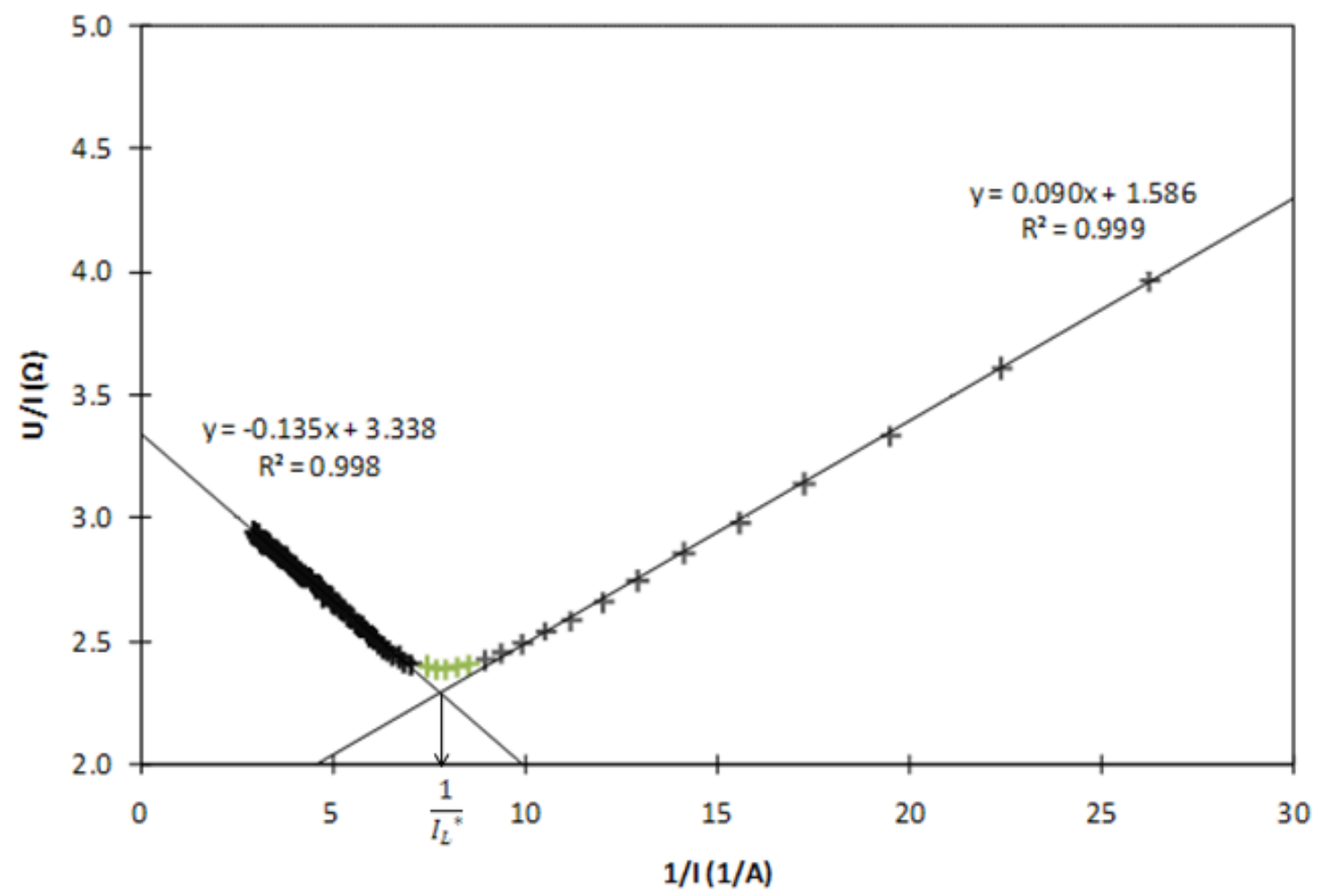

Figure 9. Cowan-Brown method for inflexion point determination 


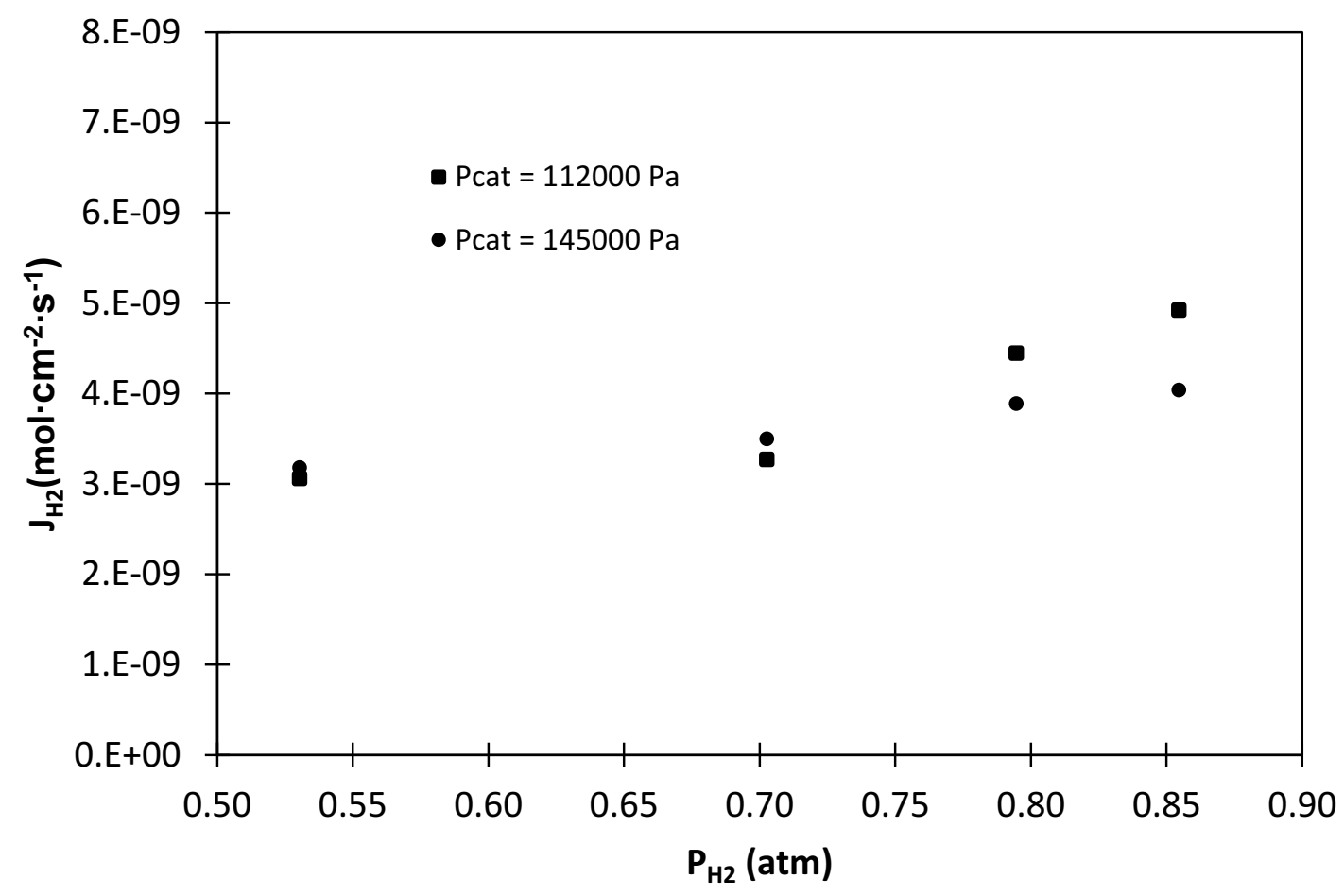

Figure 10. Hydrogen crossover flux variation with the anodic hydrogen partial pressure 


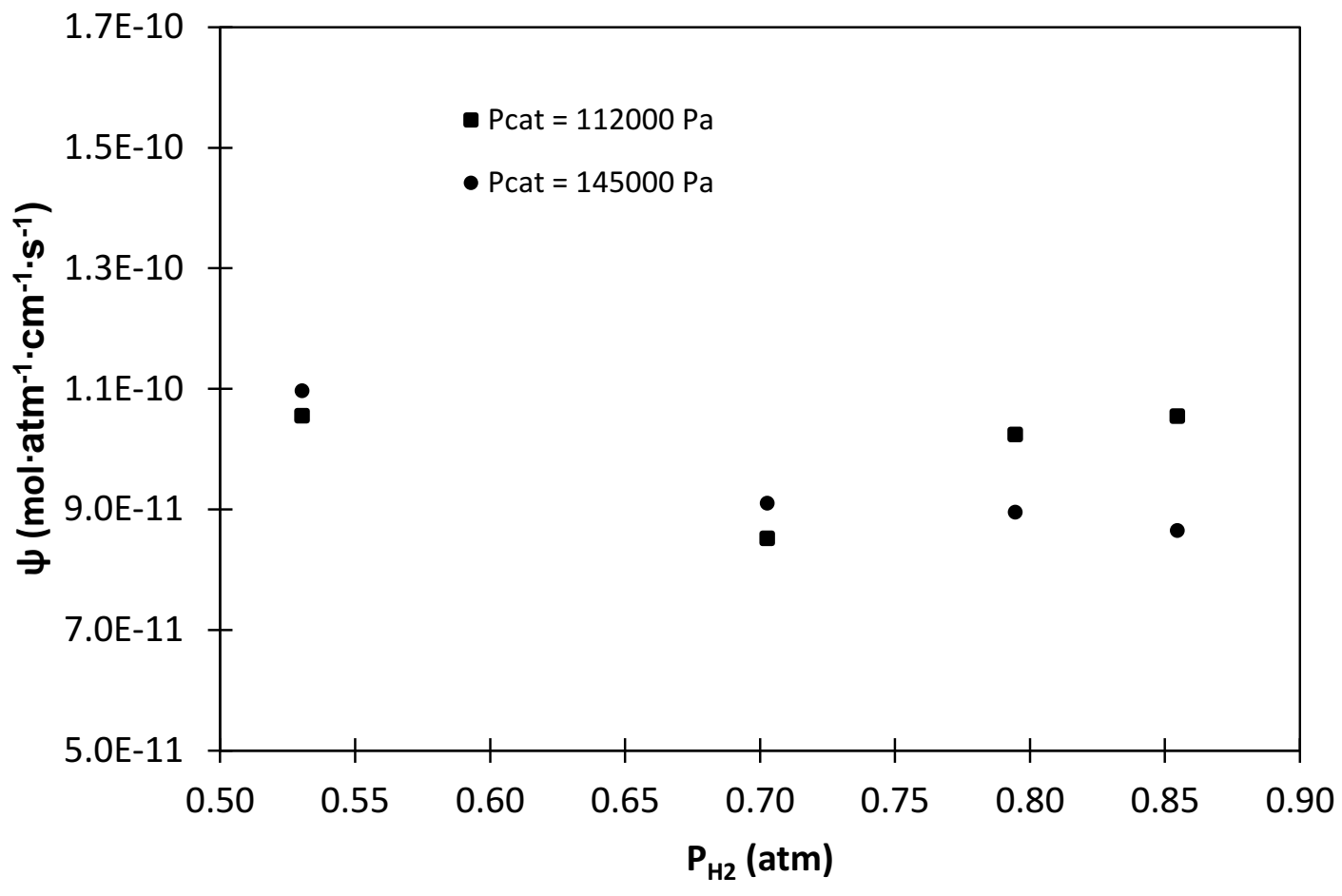

Figure 11. Membrane permeation coefficient variation with the anodic hydrogen partial pressure 